\title{
Applying Moral Development Literature And Ethical Theories To The Administration Of Taxes In Kosovo
}

\author{
William C. Campbell, Doctoral Candidate, Nova Southeastern University, USA \\ Frank J. Cavico, Nova Southeastern University, USA \\ Pedro F. Pellet, Nova Southeastern University, USA \\ Bahaudin G. Mujtaba, Nova Southeastern University, USA
}

\begin{abstract}
The population of Kosovo had suffered years of abuse, ethnic cleansing, turmoil, human atrocities, and constant conflict - the results of which plunged Kosovo into costly war. Following the war Kosovo was placed under the protection of the United Nations in 1999. Kosovo received many years of support and developmental assistance from the international community and became a sovereign nation in February 2008. It was very important for Kosovo's government to serve the needs of the people without continued oversight and intervention by the United Nations. Public institutions are vital to the success of the government. There is no institution more important to the successful development of a sovereign nation and their economy than the ethical administration of a tax authority. In the spring of 2008, after Kosovo's declaration of independence, this study was initiated to determine the moral maturity of the members of the Tax Authority of Kosovo. This study provides a review of the current situation in Kosovo and discusses ethical considerations in tax administration. The paper further provides a comprehensive discussion of ethical concerns and discusses the importance of moral development in the tax administration of Kosovo. Recommendations for managers and future research are presented.
\end{abstract}

Keywords: Ethics, moral development, Kosovo, taxes, Defining Issues Test.

\section{INTRODUCTION}

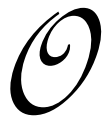

n February 17, 2008, the United Nations Protectorate of Kosovo became the Republic of Kosovo and the newest country on earth. The Prime Minister and Assembly of the newly formed nation declared Kosovo an independent state. The hope of independence was thought to bring years of turmoil to a close and open the door for prosperity and self-rule. The advancing globalization of the world has made it necessary to have a deeper understanding of the moral development of humans and their decision-making processes as they relate to professional public administration. The question thus should be posed asking if the public servant can advance morally, even though he or she may have been a victim of such atrocities.

The first author has been employed in management of public administration for over 30 years. The first author is familiar with development of emerging markets, and has worked extensively, living as well as working in the post-conflict environment of Kosovo for the last 4 years. The citizens of Kosovo wanted to see the dream of Kosovo's independence become a reality. They are dependent upon the public administration of Kosovo to make fair and impartial decisions in all decision processes. Historically, the government served the Communist régime; and there were not any motivational features that would encourage the advancement of moral development. The government worker would "play a game" of doing as little work as possible, and yet still gain compensation. That system has changed toward areas of improvement, but corruption now is taking a greater center stage. The tax administrators are compensated at less than a standard poverty wage. Such activity places the government employee, the dream of independence, and Kosovo at an excessively high level of risk. 
There is perhaps no better example of high risk and corruption than risk exposed to by members of the Tax Administration of Kosovo. Such behavior has resulted in loss of revenue and engendered a public that does not wish to practice voluntary compliance in payment of required tax, particularly where corruption might be a key factor (Sweeney \& Fisher, 1998). The government requested training and development in all aspects of anti-corruption, including comprehensive ethics training. The level of correlation between ethics training and professional and moral behavior in decision-making is of great value to the administration, much of the Balkans, and other parts of the world.

\section{A Theory of Cognitive Moral Development}

A relevant ethical concept reviewed in this study is Lawrence Kohlberg's Cognitive Moral Development theory, in particular assessing age, gender, education, and ethics training, and its effects on the members of the Tax Administration of Kosovo. Kohlberg initiated his 18-year study of American males ranging in ages from 10-16 years. His process offered each participant opportunity to examine moral challenges and select a proper course of action based on their moral reasoning (Duska \& Whelan, 1975). Kohlberg concentrated on aspects of maturity in reasoning rather than on the relationship itself. Kohlberg emphasized the aspect of constraints in reasoning. Kohlberg initially proceeded to evaluate his stages of development as pre-conventional, conventional, and postconventional (Elm \& Webber, 1994).

Kohlberg highlighted that each person moves through a process of moral development following a path. First, the path takes each person forward through various stages in increments: Cognitive development does not occur more than one stage beyond the individual's present stage. Next, individuals are moved to reason at the level above their existing level and avoid falling to past levels, while the motivating factor is emphasized due to what is described as disequilibrium (Duska \& Whelan, 1975). Each person bases his or her analysis and choices on how one associates fairness in one's reasoning processes (Rest, Narvaez, \& Bebeau, 1997).

Intelligence developed from such a study can be used to advance the development of other people's recovering in a post-conflict environment when corruption is emerging as a serious problem. The data can be used to advance solutions to comprehensive and underlying problems that exist within the government institutions of Kosovo and other institutions throughout the world (Chow \& Ding, 2002).

Kohlberg found that age and education were critical in each person's ability to reach a particular stage of moral maturity (Rizzo, 2004). Research was advanced by the development of the Defining Issues Test (DIT) by Dr. James Rest (1999). The Defining Issues Test was the continuation of Kohlberg's examination of moral maturity by advancing the development of a multiple-choice, paper and pencil instrument designed to present six detailed stories of ethical dilemmas. Each participant is asked to evaluate 12 issues based on their significance and relevance, and how each would resolve the problems. One is expected to evaluate and rank four of the issues (Kaplan, Newberry, \& Reckers, 1997). The DIT provides a P score to determine percentages from the evaluation (Rizzo, pp. 6-7).

The DIT has been examined extensively and is considered to be one of the most reliable statistical process tools in relationship analysis today. Both Rest and Kohlberg advance theories that deal with social justice. Both review a subject's ability to make a proper decision based on the subject's perception of what is right and wrong. Advancement was made to the Defining Issues Test in 1978. The new process was identified as DIT-2. The new DIT-2 provides an index and scoring system using a process called N2. It has advanced the testing mechanisms for a better behavioral analysis (Rizzo, 2004).

One can draw comparisons of other research studies, such as those conducted by Rosalind Osgood (2002), H. Michael Drumm (2002), Sandra E. Ford Mobley (2002), Karen Peek (1999), and Franck A. Hyppolite (2003), and as such draw heavily from those research projects to further expand and contribute to the field of knowledge. The DIT test often is chosen because of its ability to bring out the functional results for use in an emerging economy and a developing government as the examination applies to moral development using the Kohlberg scale (Osgood).

Each of these elements would have bearing on the moral development of the employees of the Tax Administration of Kosovo. The government administrator has a deep responsibility to build a culture of honesty and 
high ethics from the very "top," developing a positive work environment for all employees (Biegelman \& Bartow, 2006).

\section{The Philosophy of Ethics}

The word ethics is introduced as a word from the Greek meaning "ethos." The word morality comes from the Latin origin of "mores," which Peek (1999) describes as pertaining to the aspect of one's character. The word ethics was first introduced to the philosophies presented by ancient Greece.

The nature of ethics has a long history from the Greeks, Socrates, Plato, and Aristotle (Drumm, 2002). There are many theories and many philosophies as explained by Mujtaba (1997) as well as Cavico and Mujtaba (2009): utilitarianism and Kantian ethics are two important theories. At Kohlberg's highest level of cognitive moral development is the person who makes moral determinations based on reasoning from ethical principles.

Why is ethics philosophy so important? The body of ethical philosophy is quite large and expands across many years. It is critical for one to have a firm understanding of ethical philosophy in order to resolve issues dealing with ethical dilemmas. It is important to discuss aspects of ethical philosophy, because at Kohlberg's high level of moral cognizance he explained that a person only is able to make moral determinations based on reasoning from ethical theories and principles. The moral judgment helps a person to identify if a decision is moral, and the position a person takes as to the decision must be recognized (Kohlberg, 1984). This would require each person to complete such an analysis to understand the development and foundation of ethical philosophy through its very roots, and to proceed forward from the many changes and perceptions across various schools of thought (Kohlberg, 1969), yet it is impossible.

Jean Piaget (1896-1980). Piaget brought many thoughts forward on the psychological thought processes of children. Piaget's theory of cognitive development is the most recognized and cited in the field of study involving cognitive development (Lefracois, 1999). Piaget expanded on several aspects of social-cognitive theories, and he looked into the cognitive processes as to how children think. It traditionally was believed that all cognition occurs inside the mind and that cognitive processes are not outwardly visible but occur internally (Yanghee, 2006).

Piaget's work concentrated on children and the cognitive mental processes they used. Piaget believed strongly in the value of social interaction in the process of development (Mujtaba, 1997; Yanghee, 2006). Yanghee explained that the mind does not act solo, but interacts with the social environment from where it operates. Piaget determined that children develop their cognitive processes as they grow (Mobley, 2002). Piaget presented children with various problems, provided freedom to work through those problems, and assessed the results of their performance. The summation of Piaget's studies concluded that children process reasoning through a series of stages involving rules, responsibilities, and ultimate obedience to authority. It is through this process that children learn and develop (DoBell, 2007; Mujtaba, 1997).

Piaget introduced a three-step process of analyzing experiences. DoBell (2007) explained that Piaget called the first process reviewing experiences as reflective abstraction, applying those experiences to practical situations, known as empirical abstraction, and reorganizing those existing experiences into a final new stage of cognitive development called hierarchical integration. Piaget describes this system as increasing levels of hierarchical difficulty. Drumm (2002) cited that Piaget highlighted four stages of cognitive development used to process new information. The stages included sensorimotor, preoperational, concrete, and formal operations (Drumm). Piaget was a firm believer in the process of adaptation and accommodation (Cavanaugh \& Blanchard-Fields, 2002; Mujtaba, 1997).

Piaget's research provided the foundation for Lawrence Kohlberg's later work on cognitive moral development (Mobley, 2002). Piaget's work has been described as a foundation in understanding the learning process (Drumm, 2002).

Lawrence Kohlberg (1927-1987). Kohlberg was a respected psychologist and Harvard University professor who provided more support in linking the practical application of ethics philosophy to real work. Kohlberg (1984) 
followed Piaget's assumptions and techniques in his analysis of cognitive moral development. Kohlberg, like Piaget, is extensively quoted in numerous articles. Kohlberg followed the works of Jean Piaget in order to have a deeper understanding of cognitive moral development. Kohlberg moved more toward the field of moral education; and is better known for his concepts that human moral development progresses through a series of cognitive stages as a complete way of thinking about a particular moral issue (Kohlberg, 1984). Kohlberg is recognized as the first scientist to compile data showing moral decision-making as a time-consuming developmental process where a person must develop mentally and physically (Jones, 2008).

Kohlberg developed a method to test and analyze moral reasoning through his analysis of cognitive moral development (Cavico \& Mujtaba, 2009; Kohlberg, 1984; Mujtaba, 1997). The analysis included identifying and analyzing six stages of moral development. Kohlberg submitted his theory that stages 1 and 2 are identified as preconventional, of punishment and obedience and instrumental relativist orientation; stages 3 and 4 are identified as conventional, covering interpersonal concordance and law and order orientation; and stages 5 and 6 are categorized as the postconventional levels of morality, covering a social contract or legalistic and universal ethical principal (Kohlberg, 1969). Kohlberg believed that people must progress through each stage of his cognitive moral development model sequentially, and that the progress through the stages was irreversible (Peek, 1999).

Kohlberg (1984) cited the importance of learning through moral dilemmas, and that such a process required discussion and analysis of choice. Kohlberg supported Piaget's belief that social interaction was important for moral development (Drumm, 2002). Kohlberg and Rest later developed a methodology to group experiences into frames in order to analyze the experiences (Rest, 1997).

Kohlberg's research is widely accepted as foundational and has been the topic of hundreds of articles and vast amounts of research throughout the world (Rest et al., 1997). Social scientists have provided vast information in most areas of research, but some of the most important areas often are neglected. Sandra Christensen (2008) explained that there has been limited research as to why people make decisions that are contrary to law or why they make decisions that overall are considered unethical. There is even less research available in post-conflict countries. Additional continuing research is necessary to explain why people make such decisions, especially in a public institution, when so many people are dependent on their decisions for the safety, efficiency, productivity, and overall good of the people (Christensen, p. 451).

Kohlberg's (1969) six-stage model is presented in Table 1. The cognitive moral development model is recognized in helping explain issues of ethical and social responsibility.

Table 1 - Kohlberg's Six-Stage Model

Six Stages of Kohlberg's Moral Development

What is Considered to be Right

Level One - PRE-CONVENTIONAL

Stage 1 - Obedience and punishment

Stage 2 - Instrumental purpose and exchange

Level Two - CONVENTIONAL

Stage 3 - Interpersonal accord, conformity, mutual expectations

Stage 4 - Social accord and system maintenance

Level Three - POST-CONVENTIONAL

Stage 5 - Social contract and individuals rights

Stage 6 - Universal ethical principles
Following the rules in effort to avoid punishment Following rules when in best interest

Living up to what is expected by those close to you

Fulfilling duties and supporting social norms

Upholding values and rules as social contracts and ignoring majority opinion when you are right

Follow self recognized ethical principals follow laws not principals 


\section{Cognitive Moral Development}

Cognitive moral development presented the concept that young children tend to latch onto aspects of morality (Drumm, 2002). They may recognize issues of dishonesty or be able to display courage by holding aspects of those issues in a central mental registry. Increasing moral development requires that one develop a greater understanding of morality by increasing the registry. By increasing the number of aspects, one is able to identify the different issues and have a better understanding of those issues, but also is able to recognize when competing claims emerge so one can build skills to help oneself better determine the best course of action (Drumm).

Cognitive moral development has independent and direct influence on whether a person's actions are ethical (Trevino \& Youngblood, 1990). Those who act in higher stages of cognitive moral development are expected to act more ethically (Trevino \& Youngblood). The heart of the cognitive development process is the system of stages set out by Kohlberg (1984):

Level One: Pre-Conventional - Kohlberg (1969) explains that the first level begins as a child. A child learns cultural rules and labels of what they perceive to be right or wrong. The first stage associates this to be more physical consequence oriented toward threat or punishment. The second stage is a personal recognition that the best or correct behavior recognizes that one must act in one's own interest.

Stage 1: Punishment and Obedience - Physical consequences determine right or wrong, good or bad. Punishment avoidance and deterrence takes the lead (Kohlberg, 1969).

Stage 2: Instrumental Relativist - Stage two involves taking the actions that best suit one's needs and others. Laws of reciprocity take the lead from a fair play sense or sense of trade. "If you take care of me, I will take care of you" (Kohlberg, 1969).

Level Two: Conventional - The conventional level of moral thinking requires that the person recognize the perceptions of others in their actions and behaviors. The issues of social conformity and peer opinion take the lead. Each person wants to be part of the group (Kohlberg, 1969).

Stage 3: Interpersonal Concordance or "Good Boy/Nice Girl" Orientation - Behaviors are evaluated as perceptions of others and often are evaluated as to perception of intention rather than the fruits it produces (Drumm, 2002).

Stage 4: The law and order orientation begins with the individual becoming oriented toward authority. It is necessary for the person to respect rules and laws as well as the legal system. This stage includes recognizing a social order and the social welfare of others for the sake of order (Kohlberg, 1969).

Level Three: Postconventional - The postconventional level also is known as the principled level of moral thinking (Kohlberg, 1969). Drumm (2002) cites Kohlberg in saying that few attain this level. Moral values and principles at this level are defined and understood.

Stage 5: Stage 5 requires one to have a sincere interest in the welfare of others (Kohlberg, 1969). Drumm (2002) cites passages describing stage 5 as having a degree of utilitarianism. He expands by saying that stage 5 holds individual rights and societies' standards in high regard. There is recognition that a certain amount of rules and regulations are necessary in order to reach a consensus. Laws may be reexamined to determine optimum result for social utility (Kohlberg, 1969).

Stage 6: Stage 6 recognizes a universal ethical principle orientation. A person at stage 6 is able to make a conscious assessment and chose the best decision based on self-evaluated and selected ethical principles (Kohlberg, 1969). Drumm (2002) explained that principles are not concrete moral rules, and cites examples as The Golden Rule and Kant's Categorical Imperative.

Not everyone endorsed Kohlberg's theories. Carol Gilligan, a student of Kohlberg, challenged his theories on cognitive moral development (Jorgensen, 2006). Gilligan believed that Kohlberg failed to completely score females accurately in his moral development interview (Jorgensen). Gilligan believed there were significant differences in the perceptions of ethical variables viewed between men and women. Gilligan personally believed that she provided more depth or perspective to and thus enlargement of Kohlberg's theory, and consequently did not refute it (Jorgensen). Many have come to theorize that Gilligan was moving into a feminist philosophy (Jorgensen).

James R. Rest (1941-1999). Dr. James Rest followed Kohlberg's work closely. Rest was a professor at the Department of Educational Psychology at the University of Minnesota. Rest was responsible for founding the center 
for ethical development in 1982 (Drumm, 2002). Rest supported Kohlberg's development model and, with his colleagues, developed what was known as the neo-Kohlbergian approach (Rest, Narvaez, Bebeau, \& Thoma, 1999). Rest (1997) built upon Kohlberg's work and composed his four elements, or stages, of his model of ethical reasoning. Rest deviated from Kohlberg's model. While Kohlberg supported a belief that each person moved through inflexible stages, Rest believed that each person uses a process of preferences, and a gradual increase in moral development is developed through that process (Rest et al., 1999).

Under Rest's (1997) model, the first stage required that each person would acknowledge the ethical issue. The second stage required the individual to make a moral decision in choosing the proper direction. The third stage required each person to rationalize their position and recognize the moral aspects and consequences of their decision, while the fourth and final stage required a moral choice to be made. Rest believed failure could occur if there was a weakness in any of the four components. Rest recognized that each person may not place the best answer above any other in his or her ethical reasoning in selection of choices while at any particular stage (Christensen, 2008).

Rest developed a Defining Issues Test (DIT) to determine levels of moral reasoning (Rest et al., 1997). The DIT was built upon Kohlberg's work in moral reasoning (Pennino, 2002). It is a multiple-choice, groupadministered, and computer-scored measurement. The DIT presents ethical dilemmas which are schemas that must be assessed by the reviewer; and a judgment must be made and a position selected as to the various levels of importance. The instrument is to be completed with pencil and paper, where each subject must make an assessment and make the selection based on their personal view of moral significance. The DIT is considered valid and reliable and has established itself as the best tool to measure moral judgment. The test contains six dilemmas, of which three are Kohlberg-style dilemmas. Rest believed that Schemas provide cognitive structure, where a person could develop a stronger perception of an issue and organize and process the information within that structure (Jones, 2008).

The DIT identifies the level of moral maturity as a dependent variable. Researchers have compiled large amounts of information from the DIT studies, which confirm Kohlberg's development theory. The new DIT-2 test was developed in 1998 by Rest, Narvaez, Thoma, and Bebeau (as cited in Bebeau \& Thoma, 2003). The new DIT-2 is shorter than the previous DIT, and appears to show a stronger degree of reliability (Bebeau \& Thoma). It is believed that the shorter streamlined test will work more effectively in a post-conflict environment (Bebeau \& Thoma).

The DIT utilizes three scores: $\mathrm{P}, \mathrm{D}$, and $\mathrm{U}$ scores. The $\mathrm{P}$ score is a value-based score on a postconventional principled index of morality score. It almost always is explained as a percentage of the calculation from $0-100 \%$ (Griffin, 2007). The D score, known as the Davidson moral index, represents a calculation based on a scale analysis of the DIT-2 results. Rest (1986) developed the U score for those utilizing other than justice-based analysis for decision process evaluations. Rest devised the utilize (U) variable so that it would identify when others are utilizing processes other than Justice systems to make a determination or selection in decisions. Those obtaining low scores are those who did not use a justice-based analysis to arrive at their choices.

The DIT-2 provides a new index, the N Score, which outperforms the P Score on aspects of the construct validity (Bebeau \& Thoma, 2003). The N Score is composed in two parts: This includes the P Score and calculations providing the amount to which personal interest items receive lower ratings than ratings awarded to items in the higher stages. That score is combined into one collective score for each tested subject by simply adding the P score to the rating data and multiplying by three (Bebeau \& Thoma). This researcher has elected to use the DIT-2 for these reasons. Rest, Thoma, and Edwards (as cited in Jones, 2008) reported that the DIT has been utilized over 1,000 times in empirical studies in over 40 countries.

A person must be able to read at the 12-year-old reading level to understand the testable concepts. A key concept is that the more opportunities a person has to realize ethical standards, the more likelihood there will be for an acknowledgement of those standards. 


\section{Key Potential Influences of Moral Development}

Age. A number of studies have been completed that analyze a person's age in respect to the decision-making process. For many years people associated age with the ability to make a better or more ethical decision. It was thought that an older person was permitted to learn aspects of right or wrong through experiences, and the older the person the more experiences. There has been conflicting research in both directions as to the validity of age in the ethical decision-making process. More research has been found that provide contradictions in both directions (Kohlberg, 1984).

Research conducted by Jones (2008) on small business practitioners indicated there were no visible relationships between age and the moral maturity of her tested subjects. The participants from what Jones called Generation X (1965-1981) revealed higher development scores (25.28) than those she classified in the Baby Boomer generation (1946-1964) with a score of 23.35 and her Generation Y (1982-2001) with a score of 19.50 (Jones). The results were consistent with studies completed by Kohlberg (1984). Kohlberg identified greater emphasis of influence by one attaining a higher education. Griffin (2007) completed a comparative analysis on professional school counselors and interns. Griffin concluded that age had the greatest determinant as a positive influence on aspects of awareness.

Post secondary education. Many theorists have believed that post secondary education has an effect on an individual's ability to make a moral assessment. Rest et al. (1999) believed that education increases one's ability to perform professionally, but also influences one to increase the skills of one's moral compass in order to better reason through ethical processes. Rest's longitudinal study determined that higher education is highly related to postconventional development (Rest et al., 1999).

Maitland (2006) conducted research on the moral development of city and county public administrators for San Francisco. Her research involved conducting an analysis of three different departments. She submitted 3,047 DIT surveys and received 148 surveys in return. Maitland was able to extract valuable data from 98 of those returned. Maitland analyzed the results of 98 DIT scores and found that research revealed there was no significant relationship between higher education and moral maturity as tested by the DIT-2. Both groups were tested, and each represented college senior and college junior levels. Maitland did report that the DIT-2 did not provide a choice for a bachelor's degree.

Jones (2008) additionally concluded that there was no difference in the levels of moral maturity and education for the small business professionals completing the survey. Jones concluded her research was valuable, as education did not show an important contribution to the development of moral maturity within small business professionals, and thus is not a significant tool in their development at the work site.

Ethics training. Jones (2008) explained that savvy business managers utilize ethics training to set the moral "high road" for their employees and aid them in developing a moral vision of where to go. Jones additionally explains that research demonstrates there is not only a need to follow company policy but to ensure one has an idea of how to go the right direction when facing critical choices in life. There have been multiple demonstrations from the results of work from those who have received ethics training. Many public institutions train ethics in an effort to increase ethical performance. There are thousands of ethics courses taught each year on college campuses across the U.S. and throughout the world (Rest et al., 1997).

There appears to be a significant weakness in opportunity for training in how to respond to an ethical problem (Jennings, 2004). Jones (2008) reported 56 subjects participated in her study, while 67\% indicated receiving some ethics training ranging from 1-2 hours. Jones administered the DIT and determined that there was not any significant difference between those indicating they had received formal ethics training and those indicating they had not received ethics training. Jones cited a finding she believed was especially significant in that participants who indicated they had no ethics training scored the second highest moral maturity means score.

The research was valuable in that the assessment was able to determine that the participants would have gained their ethical development from some processes other than through what they believed was the ethics 
trainings. Jones (2008) was able to determine that there was not any statistical significance between ethics training and moral maturity. Jones postulated that perhaps it was other areas that significantly increased a participant's ability to make a moral decision. Jones believed that the informal networks and peer groups did more to influence a role model type of behavior within each institution. Jones determined that while $67 \%$ of the small business managers indicated they had participated in ethics training, the lack of significant findings suggested that their level of exposure to ethics training may have been too short, too insignificant, or without the necessary depth to make a difference in behavior.

Gender. Blasius (2007) conducted research on school officials, both teachers and principals, to determine their leadership style. In that analysis, he presented them with the DIT-2. The DIT-2 was administered in an effort to determine the principal's post conventional moral reasoning level. Blasius believed that because the principals of the elementary school systems were female, gender was a significant underlying factor in determining moral development.

\section{Dissertations and DIT Research}

The DIT and DIT-2 are valuable tools. Many people throughout the world are using it today. The DIT is providing valuable research on many topics and in many areas. One such area of research was conducted by Griffin (2007). Griffin conducted a comparative study of professional school counselors' and school counseling interns' multicultural competence and moral development. Griffin conducted research to determine the levels of moral maturity and other aspects of culture for school counselors.

Griffin (2007) theorized that a high level of maturity would be a determining factor in issues of counseling competency. Griffin asked a number of questions to include issues associated with demographics of the group selected for testing. Griffin specifically wanted to know issues related to experience, aspects of multicultural training, and points about supervision. Griffin additionally posed questions about demographic variables, such as age, sex, and race. A final question was asked about whether the participants had discussed aspects of race with their students.

Griffin (2007) reported that counselors did not receive training in supervision, yet were expected to train others. Griffin tested 61 professional school counselors and 31 school interns. Griffin reported finding significant differences between the ethical moral maturities of the two age groups. Griffin reported using the Defining Issues Test and a Multicultural Counseling Competence and Training Survey along with a general demographic questionnaire to determine the levels of moral maturity along with issues of variance. Griffin found no serious differences between the two counseling groups.

Jones (2008) conducted research utilizing the DIT-2 to determine moral judgment and ethical decisionmaking of business professionals in small businesses. It has been determined that ethical processes reduce the likelihood of misconduct and reduce the risk of fraud (Biegelman \& Bartow, 2006). Jones believed that high level ethical processes were important to many executives. Jones set out her research question as, "Is there a difference in moral development and ethical decision making of Small Business professionals based on ethics training, education level, gender, age, company position, management VS non management, and moral maturity levels?"

Jones (2008) was able to determine that there were no significant differences in aspects of education, age, gender, ethics training, or position within the organization in relation to determining influence on the ethical moral maturity levels of decision-makers for those who took the test. Jones expressed that scores demonstrated great similarity between managers and non-managers. This supported the belief that the research was valuable in that it was able to explain to some degree that there was evidence to show an interactive role modeling that encourages development through greater degrees in communications rather than ethics trainings (Jones). Jones recommended adding team collaboration, mentoring, and increasing informal networks into small business operations processes.

Maitland (2006) conducted research on public administrators serving the city and county of San Francisco. Maitland set out to determine the cognitive moral development of the public administrators. Maitland was interested in discovering answers to four questions: 
1. What is the average stage of moral development achieved by Special Assistants?

2. What is the average stage of moral development achieved by civil servants?

3. Does a significant difference exist between the moral development stages of Special Assistants and Civil Service employees?

4. Are there any significant relationships between the moral development of both Special Assistant/Civil Service employees and various participant demographic variables, such as gender, education level, age, cultural origins, and formalized ethical training?

There have been five public sector-based, DIT-based dissertations written at Nova Southeastern University. Drumm (2002) highlights that the first DIT was completed by Dr. Karen Peek in 1999. Peek covered appointed federal officials. The second was written by Dr. Rosalind Osgood in 2002. Osgood covered elected officials at the municipal level. The third was written by Dr. H. M. Drumm in 2002. Drumm covered public officials working in the fire service. The fourth was written by Dr. Susan Mobley in 2002. Dr. Mobley covered considerations in public administration practices. The fifth was written by Dr. Franck Hyppolite in 2003. Hyppolite covered the influence of culture in moral development in local government.

Peek (1999) explained that Rest conducted a 10-year longitudinal study in which Rest discovered that education was a more powerful predictor to determine the advancement of moral development than age. Rest reported that education tends to make the DIT score higher.

\section{Public Administration and Ethics in Government}

A solid ethical public administration is the foundation of good governance. It is necessary to build and maintain an honest public administration in order to carry out the directives of elected public officials throughout the land. This is not only important to the United States but to the world. There have been errors in judgment presenting issues affecting the image and integrity of high-ranking public officials. Such issues not only serve to discredit public officials personally, but professionally.

In the late 1880s, the passage of the Pendleton Act was a step toward separating politics from the public service of employees. Osgood (2002) explains that President Wilson's goal through the Reform Era (1883-1971) was to set a framework for the government to operate outside of politics. The Reform Era set out the body or outline of a Code of Ethics to guide government managers in developing codes for the members of their institutions. Osgood cites that the Pendleton Act was designed to offset the issues and problems caused by the "spoils system" so indicative of the post Civil War reconstruction periods. Osgood also cites that Frederick Mosher reflected on Protestant Ethics in his review of resolving moral obligations.

Osgood (2002) reflected on the New Public Administration Era of the 1970s and 1980s, as she explained that it was the self-actualization period in that public officials need to bring out their own personal values as they express their own personal codes of ethics and make moral decisions. Peek (1999) explained that ethical problems within the government bring about compromising situations, breaches of trust, and general misconduct. Peek further explained that the perception the employee has about the ethical climate or environment of the work institution may affect a number of ethical considerations in decision-making. The employee's perception becomes critical if the climate breeds unethical behaviors, as such behaviors can place the very stability of the government in peril. Having a government in peril has been one of the most significant social causes for the Reinvention Government Era, which exists now.

Hyppolite (2003) cites Frederickson and identifies the Contemporary Era, also called Spiritualism, in Frederickson's (1997) The Spirit of Public Administration. Frederickson sought to pursue the better parts of public administration. Such an attitude supported integrity, morality, and honesty. There was a specific and visible change as the government sought greater personal accountability.

Organizations such as the American Society of Public Administrators (ASPA) and the Association of Certified Fraud Examiners (ACFE) have sought to bring about strong codes of ethics for integrity for their members. Public institutions also have introduced codes of ethical behavior and codes of conduct. These codes have served to 
provide guidelines for behavior, but traditionally have had little effect in making a dishonest employee honest. Conflicting value systems, post war and post independence strain, low pay, political instability, limited institutional capacity, fragmented government infrastructures, and economic stress all have contributed to pressures upon public officials in emerging economies to violate their integrity.

Peek (1999) sets out the standards for ethical behavior that are necessary for all federal officials to follow, as established by part one of Executive Order 12674. The 14 elements set a foundation for all employees to follow as it applies to ethical service. Peek explained that two predominant themes apply to federal programs that design ethical standards. The first theme is to make sure the government operates effectively and efficiently. The second theme is to minimize waste, fraud, and abuse. There are key elements that set out the standards of federal government administration, which include to maintain public trust; to swear and demonstrate loyalty to the constitution; to avoid conflicts of interest, such as using confidential information for private gain and seeking gifts associated with an official action; to produce honest effort in work; to make no unauthorized binding commitments; to not use one's public office for private gain; to act impartially and provide no preferential treatment; to protect federal property; to not engage in conflicting outside employment; an agreement to disclose waste, fraud, abuse, and corruption; requirements to satisfy all financial transactions; to adhere to all laws and regulations; to support equal and fair treatment for all; and to avoid any action of perceived impropriety. Such behavior is not merely an issue of concern for the United States, but other countries as well (Selcuk, Brabeck, Satiani, \& Rogers-Senn, 2003).

\section{Ethical Problems in the Public Sector}

Ethics are important for every country and every government. People tend to evaluate government employees based on their behavior (Perkumiene, Adamoniene, \& Merkiene, 2007). In 2004, Darlene Druyan, a procurement officer in the United States Air Force, was sentenced to 9 months in a federal prison for issues of corruption because she traded contracts to Boeing for promises of employment for herself and her family (Salacuse, 2008).

Ethics are important publicly and privately. Countries all over the world are seeking to create more transparency in order to reduce the risk of corruption by public officials. The massive economic growth by economic giants, such as China, has led to greater forms of corruption. The Chinese have estimated that $20 \%$ of public project funds leak into private hands each year (Chow \& Ding, 2002). This accounts for 15\% of China's GDP, according to Transparency International (as cited in Chow \& Ding). Humphrey (as cited in Hung, 2008) explained that while many attribute the large "waves" of corruption as administrative and ethics problems, there also is argument that it is due to a lack of commitment and discipline from government officials.

Ethical problems tend to present the public administrator in a negative light. Such problems have had a negative effect on the work product and work environment (Perkumiene et al., 2007). At the time of this writing, there is no research into the moral decision-making processes used by administrators within a post-conflict country. Many European countries in the Balkans have been hesitant to establish clear positions on issues such as conflict of interest. In many cases, public officials receive personal benefit from their official acts. This reduces the ability to obtain a critical analysis of proper choices in decision-making from an impartial government official who might be encouraged to support a substandard process or accept a less than adequate bid in order to achieve personal gain. Ethical behavior disengages the threats and effects of corruption in order for the economy to stabilize and to develop an effective political process so it may work effectively (Erakovich, Dragoljub, \& Wyman, 2006). Erakovich et al. cite the massive cost of corruption in the Balkans.

Erakovich et al. (2006) explained that in 2000, a Senior Administrator for the European Union, Alexander Bozhkov, was removed for allegations of corruption. He further explained the need for public trust. It is the citizen's trust of the public official that affects laws, values, and institutional development. He explained that public citizens expect public employees to serve the government by respecting the public resources and making their decisions based on social equity.

Government processes and systems must be based on the social needs of the public rather than merely blindly following self-serving policies, rules, and regulations (Erakovich et al., 2006). A democracy is based on 
trust, and, as such, the "building fibers" of a new democracy can be especially fragile. Such a democracy is based on trust in public officials. A democracy without a code of conduct or a government that fails to follow a code encourages disrespect among the ranks (Cohen, 2008). The code is a foundational process of recognizing the need for professional behavior where individual ethics fail. This is considered a byproduct of moral judgment (Cotter \& Greif, 2007).

Morality looks into the practices one uses, and through that analysis determines the values connected to each practice. Philosophy divides morality into two schools of ethics: teleological and deontological. Teleological subscribers believe that the moral value of the behavior is determined by the behavior's consequences, while the subscribers of deontological theories believe that the methods or intentions of the behavior are the most important. Utilitarianism is part of teleological belief and, as such, is consequence-based (Osgood, 2002). Positive moral behaviors are considered to be duty-based, but not based on legal foundations or positive outcomes.

Managerial members of society who subscribe to and develop standards of ethics based on either teleological or deontological theories help to shape not only their own moral code, but also the moral character of the processes of those who serve them (Osgood, 2002). The analysis of the literature would suggest that public administrations establish rules and codes of conduct based on moral processes in the development of government (Osgood). Many look at business ethics to determine the best direction to go toward professional business processes (Peek, 1999).

Osgood (2002) explained that previous works document that ethical misdeeds of the late 20th century were linked to elected officials or party affiliates rather than career employees. Kohlberg's cognitive moral development (CMD) model and research has been used for the last 17 years. The research of Kohlberg and Rest (as cited in Rest et al., 1999) was critical in the development and furthering of research on governmental, social, and ethical issues. Drs. Peek (1999), Osgood, Drumm (2002), Hyppolite (2003), and Mobley (2002) all drew from Kohlberg's CMD model as well as Dr. James Rest's Defining Issues Test (DIT). Such studies advance the effect by helping to shape members' ethical behaviors. Organizations have conducted analyses of codes of ethics and policies in order to determine if there is a conflict (Peek).

The issues may arise from the same concepts, and several do hold many of the same foundational beliefs. One must seek to understand how moral decisions are made and on what foundation they are based. Judge William H. Pryor (2008), a public official, explained that he believed his deeply held faith set out a foundation for his professional service as a Judge in understanding his oath of office, sustaining his moral duty to obey the authority he was given, his personal responsibility to work diligently, and his responsibility to provide honest service. Judge Pryor explained that his own perception of moral courage and dignity created a challenge for his very appointment to the Bench. Judge Pryor, a devout Catholic, further explained that his confirmation hearing presented a challenge to his deeply held religious beliefs. The final opinion of the hearing was that regardless of his religious values, he did not allow any interference in his interpretations, as he always served the law (Pryor). Such values present a foundational challenge for public officials in making moral decisions.

\section{ETHICS AND THE GOVERNMENT OF KOSOVO}

Kosovo has suffered through many atrocities of war, and many in the population experienced such atrocities at the hands of governmental officials from the previous régime. Government officials designed a system based on an ethnic apartheid process, prohibiting citizens from access to education. Many were required to sign agreements to endorse and support the Serbian régime in order to attend any schools. It is reported that less than 10\% signed such agreements (Muharem Ibrahimi, Permanent Secretary Ministry Finance and Economy, personal communication, May 16, 2008). Many citizens were restricted from having public positions in public services. The problems continued to escalate into serious human rights violations. Many Europeans believed that some attitudes were prevalent due to theological differences between Christian and Muslim philosophies, which perhaps caused this problem. Srnka, Gegez, and Arzova (2007) explained that both Christians and Muslims find lying, cheating, deceiving, manipulating, bribery, and nepotism unethical. 
NATO initiated bombing of Serbia once atrocities came to light, and in turn Serbia immediately initiated a process of ethnic cleansing in Kosovo. Babamusta (2007) reported that over 11,000 Kosovar Albanians lost their lives and were buried in 529 mass graves throughout Kosovo during a 3-month campaign of ethnic cleansing in 1999. Babamusta further reported that over 1.5 million citizens were forcibly expelled from their homes in 1998, and 58 members of one family living in one Kosovo town were murdered. There were countless rapes and other atrocities reported to have been committed by the Serbian Régime on the Albanian population. This horrendous behavior had a profound effect on the internal and external reactions of citizens inside and spectators outside of Kosovo (Babamusta). Most of the actions were done by the military and organized by public officials.

The following months after the war lead to a period of unrest, political instability, and post-conflict development (Babamusta, 2007). The months turned into years, and local members of the Kosovo population were appointed to public positions in several high-level government institutions. Many citizens of Kosovo never had previously held a position in a public office. Others had served in positions that were under the former Yugoslavian or Serbian régime. There also was a certain degree of discrimination. Many women were discouraged from taking part in any government positions. There was a perception that women were weak. Over recent years the UN and USAID have been instrumental in encouraging the participation of women in Kosovo's public service. Women now are found in many positions throughout the government. A study completed by the World Bank (Hunt, 2007) determined that there are less incidents of corruption in governments where women hold governmental positions. It has been stated that in many cases, the employment of women in public service demonstrates renewed public trust (Hunt).

Most of the members of the Kosovo government are relatively young. In a recent survey conducted by the government, not only had most employees never served a government institution, but $80 \%$ were under the age of 35 (personal inventory of the first author). The majority of Kosovar government employees have received a formal education through the once Yugoslavian, later Serbian, and now Kosovo managed University of Pristina (personal observation of the first author). Most had not received any training in ethics or formal decision-making processes. A number of employees had experienced an escalation in atrocities and discriminatory behaviors as citizens living in Kosovo during the war. The research answers key questions to determine if the above factors have had an influence in the development of ethical moral maturity of the members of the tax administration.

A number of incidents and allegations of corruption have occurred that have brought a number of public officials into disrepute. Such behaviors additionally discredit the organizations they serve. Equally important is the risk of false allegations of corruption when it is not present and the damage it causes to the reputation of the innocent. The research herein thus will assist in developing policies and procedures that assist improving the further development of each person's ethical moral maturity.

Many public organizations serve to meet the needs of Kosovo. The Tax Authority of Kosovo serves as a key component of the Ministry of Finance and Economy. It is perhaps one of the most key components of the financial "bloodline" or "circulatory system" for Kosovo. The Tax Authority of Kosovo is required to collect taxes and accomplish audits on the population and businesses of Kosovo. This is done in order that the government may obtain funds to operate. The public has shown more willingness to pay taxes when they feel their funds will be used properly.

Some members of the Tax Administration of Kosovo have been accused of engaging in issues of integrity violations. In order to reduce compromises of integrity, the Tax Authority of Kosovo enrolled all managerial members of the Tax Authority of Kosovo in a 5-week long ethics training program. Many government managers had speculated that employees of the Tax Administration may have been tainted from their time in Kosovo during the war, and others speculated that many may have become jaded toward public service for the time they may have served the former Serbian or Yugoslavian régime.

Code of conduct. The Tax Administration of Kosovo additionally adopted a code of conduct. The code of conduct highlighted 14 factors that each employee is responsible to acknowledge and support. 


\section{Recommendations for Ethical Behavior in Tax Administration}

The following recommendations will serve great importance to achieve a morally developed tax administration in Kosovo. Each element has a purpose and would provide a firm foundation for the new government.

Establish a professional code of ethics. This allows the institution to implement countermeasures to compensate for areas of weakness or create options of resolution where issues of transparency may come into question. It additionally allows the institution to place countermeasures in the employee code of conduct to reduce problems and eliminate unproductive patterns of behavior. It might establish rules of transparency that are unit, departmental, or ministerial wide. It helps one to understand the expectations of what the institution is required to follow.

Provide initial new employee and annual ethics and refresher training. This allows the employee to start with a firm foundation understanding the rules of the administration, laws, and expectations. This will allow the employee to gain a solid foot hold from the beginning, thereby reducing mistakes before bad mistakes are developed into permanent behaviors. The training should include various dilemmas that a public administrator might face, such as bribery or tax collection issues.

Initiate and develop safe hiring practices. This allows for the initial selection, interviewing, and hiring of a functional workforce. It helps the institution if the hiring is done correctly in the first place. This allows the organization to assess the organizational needs of the institution and establish measures to complete adequate background investigations, conduct proper interviewing, and measure skills based on character and aptitude for long-term development.

Invite professional societies. Kosovo should invite professional societies to become an integral part of the development of the public work force. Such societies might include the Association of Certified Fraud Examiners, Society for Human Resource Management, and other such associations where professionalism and integrity are key components for participation in the program. This would allow members opportunity to gain further training and development and provide a professional network of key professionals.

Professional training for association with the public. Provide a regular training session on how to greet and treat the public. This should include behaviors, dress codes, and professional conduct. Further recommendations will be forthcoming based on the analysis of the data.

Study the process and conduct further research. Some research questions regarding Kosovo and tax administration that can be answered by future researchers through scientific studies are as follows: 1) Is there a relationship between moral maturity level and public sector employees' level of education? 2) Is there a relationship between moral maturity level and public sector employees' age? 3) Is there a relationship between moral maturity level and public sector employees' gender? 4) Is there a relationship between moral maturity level and public sector employees' ethics training? 5) Is there a relationship between public sector employees' moral maturity level for those who lived in Kosovo during the conflict/bombing? 6) Is there a relationship between public sector employees' moral maturity level for those who had previously served the Yugoslavian or Serbian government?

\section{SUMMARY}

There is detailed data on the aspects of conducting research on developing ethical moral maturity. There is limited research covered in the same aspects as it applies to public administration. There is even less research on moral maturity in a post-conflict environment. Research on assessing moral maturity in a public administration was conducted by Drs. Maitland (2006), Peek (1999), Osgood (2002), Mobley (2002), Drumm (2002), and Hyppolite (2003). Unfortunately, there is limited research available on any aspect of moral development from a post-conflict environment, such as Kosovo.

Babamusta (2007) explained in detail the uniqueness of Kosovo. Babamusta reported that Kosovo is part of what was called the "frozen conflict" concept. Babamusta explained that the geography included areas of what was 
formerly known as the Soviet Union. Daniel Fried, U.S. Assistant Secretary of State for European and Eurasian Affairs, explained that Kosovo was especially unique in that NATO had to intervene, stop, and reverse the efforts of ethnic cleansing (personal observation). Actions such as these placed an additional emphasis on the government of Kosovo due to the need to meet United Nations mandate 1244, which called for Kosovo's final status to be renegotiated. Such research on ethical moral maturity would be valuable throughout the world.

Babamusta (2007) reported that over 2,100 Ethnic Albanians still are being held in Serbian detention facilities and prisons. The research is valuable because people are a product of their environment, and the moral behavior in the work environment is in a critical condition (Cavico \& Mujtaba, 2009; Kohlberg, 1984; Mujtaba, 1997). It has been reported that one in six employees has withheld suggestions that would improve efficiency in their workplace. In a study of 800 employees in the U.S., 10\% reported that they had witnessed hostility in their workplace, and $20 \%$ had experienced becoming personal targets of hostility within the workplace each week. It has been further reported that many who witness and tend to experience violence also tend to replicate it (Pfeffer, 2007).

Future studies can provide additional research to the existing topic and body of knowledge to all who seek a more clear understanding of the study of morality and ethics in public administration, tax administrations, ethics, morality, and concepts of moral judgment as they are applied to government, especially in a post-conflict environment. It is important to remember that ethics, law, and theology are not the same thing. The preliminary reflections indicate that it is clearly evident that moral behavior is important for the ongoing development of the public servant. Ethical training does appear to have an impact on the moral maturity of the Kosovo participants as well as their exposure to living in Kosovo during the war and serving the previous government. This certainly indicates a need to pursue advanced training in the areas of ethical behavior, perhaps through introduction of training utilizing moral dilemmas similar to the real world encounters such as those experienced by a typical public servant.

The recommendations and proposed research would provide a valuable foundation for Kosovo's tax administration as well as other departments in other ministries. The results would provide valuable insight to other developing nations and emerging markets, and help to resolve tax administration issues throughout the world.

\section{AUTHOR INFORMATION}

William Campbell is a doctoral student at the H. Wayne Huizenga School of Business and Entrepreneurship of Nova Southeastern University. Mr. Campbell holds an MBA from Nova Southeastern University and a B.S. from Southwest Baptist University. Mr. Campbell serves as the Executive Director of All Points Risk Assessment LLC, a global development firm designed to identify potential problems in management and develop public administration from the ground up, conducting ethics assessments and fraud risk analysis with a general risk assessment on such organizations. Mr. Campbell just returned from Kosovo where he worked for the last 4 years developing the Ministry of Finance and Economy in Kosovo with special concentrations on the Tax Authority, Customs, and the Central Bank. He previously worked as a Senior Special Agent for the U.S. Treasury Department. His service included working for over 20 years as a presidentially decorated Investigator/Agent Task Force manager where he conducted and managed countless investigations on various aspects of fraud to include international business fraud. $\mathrm{He}$ has conducted assessments on over 40 private and public corporations. He is a Certified Fraud Examiner and worked for 3 years as the worldwide Chairman of the Professional Liaison Committee for the Association of Certified Fraud Examiners. He additionally has worked as an adult trainer/educator for almost 20 years.

Frank J. Cavico is a professor of Business Law and Ethics at the H. Wayne Huizenga School of Business and Entrepreneurship of Nova Southeastern University. In 2000, he was awarded the Excellence in Teaching Award by the Huizenga School. In 2006, he was honored as Professor of the Year by the Huizenga School. Professor Cavico holds a J.D. degree from St. Mary's University School of Law and a B.A. from Gettysburg College. He also possesses a Master of Laws degree from the University of San Diego School of Law and a Master's degree in Political Science from Drew University. Professor Cavico is licensed to practice law in the states of Florida and Texas. He has worked as a federal government regulatory attorney and as counsel for a labor union; and has practiced general civil law and immigration law in South Florida. 
Pedro Pellet is a professor of economics and statistics at the H. Wayne Huizenga School of Business and Entrepreneurship of Nova Southeastern University. He has been a permanent member of the University since 1982. $\mathrm{He}$ has been a full-time teacher at Nova Southeastern University since April 1, 1982, and has attended higher education centers in Cuba, Great Britain, Puerto Rico, Spain, and U.S.A. Dr. Pellet completed the requirements for a Baccalaureate Superior from the Universidad Complutense de Madrid, Spain; a B.Sc. in Biology (Summa cum Laude) from the University of the Sacred Heart, Santurce, Puerto Rico; two B.A.'s (Summa cum Laude) in Economics and Political Sciences and an M.A. in Economics (Awarded the highest honor in Economics: The Economics Medal) from the University of Puerto Rico, Río Piedras Campus; M.Phil in Economics from the London School of Economics and Political Science, U. K.; and a Ph.D. in International Affairs with specialties in Economic Development and the Developmental Process from the University of Miami, Coral Gables, Florida, U.S.A.

Bahaudin G. Mujtaba is an Associate Professor of Management, Human Resources, and International Management at Nova Southeastern University's H. Wayne Huizenga School of Business and Entrepreneurship in Fort Lauderdale, Florida. Bahaudin has worked as an internal consultant, diversity trainer, and management development specialist as well as retail management in the corporate arena for over 16 years. Bahaudin is the author and co-author of several books in the areas of diversity management, business ethics, leadership, and cross-cultural management. Bahaudin can be reached through email at: mujtaba@nova.edu.

\section{REFERENCES}

1. Babamusta, E. N. (2007). Kosovo status talks: A case study on international negotiations. Retrieved from ProQuest Digital Dissertations. (AAT 1450930)

2. Bebeau, J. M., \& Thoma, S. J. (2003). Guide for the DIT-2. Minneapolis: The University of Minnesota Press.

3. Biegelman, M. L., \& Bartow, J. T. (2006). Executive roadmap to fraud prevention and internal control: Creating a culture of compliance (1st ed.). Hoboken, NJ: John Wiley \& Sons.

4. Blasius, T. (2007). Comparison of moral reasoning and transformational leadership of public school principals using inclusive education in Michigan. Retrieved from ProQuest Digital Dissertations. (ATT 3290057)

5. Cavanaugh, J. C., \& Blanchard-Fields, F. (2002). Adult development and aging (4th ed.). Belmont, CA: Wadsworth.

6. Cavico, F. J., \& Mujtaba, B. G. (2009). Business ethics: The moral foundation of leadership, management, and entrepreneurship (2nd ed.). Boston: Pearson Custom Publications.

7. Chow, I. H., \& Ding, D. Z. (2002, Fall). Moral judgment in conflict handling styles among Chinese in Hong Kong and PRC. The Journal of Management Development, 21(9/10), 666-680.

8. Christensen, S. L. (2008, February). The role of law in models of ethical behavior. Journal of Business Ethics, 77(4), 451-461.

9. $\quad$ Cohen, D. (2008, April). Trust fund. Financial Management, 414.

10. Cotter, J. W., \& Greif, T. B. (2007). Ethical decision-making in a fast changing world. International Journal of Business Research, 7(5), 48-68.

11. DoBell, D. (2007). Models of hierarchical complexity and cognitive development: Assessing the multiliteracy pedagogy. The International Journal of Learning, 14(1), 135-143.

12. Drumm, H. M. (2002). The ethical and moral development difference of municipal department heads based on the Defining Issues Test. Retrieved from ProQuest Digital Dissertations. (AAT 3069473)

13. Duska, R., \& Whelan, M. (1975). Moral development: A guide to Piaget and Kohlberg. New York: Paulist Press.

14. Elm, D. R., \& Webber, J. (1994, May). Measuring moral judgment. The moral judgment interview or the Defining Issues Test? Journal of Business Ethics, 13(5), 341.

15. Erakovich, R., Dragoljub, K., \& Wyman, S. M. (2006). A normative approach to ethics training in central and eastern Europe. International Journal of Public Administration, 29(13), 1229-1257.

16. Frederickson, G. H. (1997). The spirit of public administration (1st ed.). San Francisco: Jossey Bass.

17. Griffin, D. C. (2007). A comparative study of professional school counselors' and school counselors interns' multicultural competence and moral development: Exploring the gap between training and supervision. Retrieved from ProQuest Digital Dissertations. (AAT 3257322) 
18. Hung, H. (2008, April). Normalized collective corruption in a transitional economy: Small treasuries in large Chinese enterprises. Journal of Business Ethics, 79(1/2), 69-83.

19. Hunt, S. (2007, May/June). Let women rule. Foreign Affairs, 86(3), 109-120.

20. Hyppolite, F. A. (2003). The influence of organizational culture, ethical views and practices in local government, a cognitive moral development study. Retrieved from ProQuest Digital Dissertations. (AAT 3144703)

21. Jennings, M. M. (2004). Incorporating ethics and professionalism into accounting education and research: A discussion of the voids and advocacy for training in seminal works in business ethics. Issues in Accounting Education, 19(1), 7-26.

22. Jones, E. W. (2008). An exploration of moral judgment and ethical decision-making of business professionals in small businesses. Retrieved from ProQuest Digital Dissertations. (AAT 3296729)

23. Jorgensen, G. (2006). Kohlberg and Gilligan: Duet or duel? Journal of Moral Education, 35(2), 179-196.

24. Kaplan, S. E., Newberry, K. J., \& Reckers, P. M. (1997, Fall). The effect of moral reasoning and educational communications on tax evasion intentions. The Journal of American Taxation Association, $19(2), 38-55$.

25. Kohlberg, L. (1969). Stage and sequence: The cognitive-developmental approach to socialization. In D. A. Goslin (Ed.), Handbook of socialization theory and research (pp. 347-480). Chicago: Rand-McNally.

26. Kohlberg, L. (1984). Essays on moral development (1st ed.). San Francisco: Harper \& Row.

27. Lefracois, G. R. (1999). The lifespan (6th ed.). Belmont, CA: Wadsworth.

28. Maitland, P. A. (2006). Cognitive moral development in city and county of San Francisco public administrators. Retrieved from ProQuest Digital Dissertations. (ATT 3243179)

29. Mobley, S. E. (2002). The study of Lawrence Kohlberg's stages of moral development theory and ethics: Considerations in public administration practices. Retrieved from ProQuest Digital Dissertations. (AAT 3053218)

30. Mujtaba, B. G. (1997). Business ethics survey of supermarket managers and employees. Retrieved from ProQuest Digital Dissertations. (AAT 9717687)

31. Osgood, R. (2002). A study of the cognitive moral development theory and ethics in municipal government. Retrieved from ProQuest Digital Dissertations. (AAT 3058556)

32. Peek, K. L. (1999). The good the bad and the "misunderstood:" A study of the cognitive moral development theory and ethics in the public sector. Retrieved from ProQuest Digital Dissertations. (AAT 9929399)

33. Pennino, C. M. (2002, December). Is decision style related to moral development among managers in the U.S.? Journal of Business Ethics, 41(4), 337-347.

34. Perkumiene, D., Adamoniene, R., \& Merkiene, R. (2007). Importance of ethics and working culture the employees of the district municipality. Management Theory \& Studies for Rural Business and Infrastructure Development, 8(1), 334-339.

35. Pfeffer, J. (2007, Fall). Human resources from an organizational behavior perspective: Some paradoxes explained. Journal of Economic Perspectives, 21(4), 115-134.

36. Pryor, W. H. (2008, Winter). Moral duty and the rule of law. Harvard Journal of Law and Public Policy, 31(1), 153-170.

37. Rest, J. R. (1986). Moral development: Advances in research and theory. New York: Praeger Publishers.

38. Rest, J. (1997). Designing and validating a measure of moral judgment: Stage preference and stage consistency approaches. Journal of Education Psychology, 89(1), 5-28.

39. Rest, J., Narvaez, D., \& Bebeau, M. (1997). Alchemy and beyond: Indexing the Defining Issues Test. Journal of Educational Psychology, 89(3), 498-507.

40. Rest, J., Narvaez, D., Bebeau, M. J., \& Thoma, S. J. (1999). Postconventional moral thinking: A neoKohlbergian approach. Mahwah, NJ: Lawrence Erlbaum Associates.

41. Rizzo, A. M. (2004, July). Comparing the Stewart-Sprinthall management survey and the Defining Issues Test. The Journal of Public Administration Research and Theory, 14(3), 6-7.

42. Salacuse, J. (2008, February). Coping with corruption. Negotiation, 4.

43. Selcuk, S. R., Brabeck, M. M., Satiani, A., \& Rogers-Senn, L. (2003, July). Validation of a measure of ethical sensitivity and examination of the ethics of previous multicultural and ethics courses on ethical sensitivity. Ethics and Behavior, 13(3), 221-236. 
44. Srnka, K., Gegez, A., \& Arzova, S. (2007, August). Why is it (Un-)ethical? Comparing potential European partners: A western Christian and an eastern Islamic country - on arguments used in explaining ethical judgments. Journal of Business Ethics, 74(2), 101-118.

45. Sweeney, J. T., \& Fisher, D. G. (1998, October). An examination of the validity of a new measure of moral judgment. Behavioral Research in Accounting, 10, 138-159.

46. Trevino, L. K., \& Youngblood, S. A. (1990). A casual analysis of ethical decision-making behavior. Journal of Applied Psychology, 75(4), 378-385.

47. Yanghee, K. (2006). A social-cognitive framework for pedagogical agents as learning companions.

Educational Technology, Research and Development, 54(6), 569-596. 
NOTES 